\title{
The deadly effects of violence against medical workers in war zones
}

$\mathrm{V}$ iolent attacks on health workers and facilities are common in war zones while laws to protect them are increasingly impotent, according to a new study from the International Committee of the Red Cross (ICRC) that suggests this problem is "one of the most crucial yet overlooked humanitarian issues of today."

The new report, A Sixteen Country Study: Health Care in Danger, is based on an analysis of reports from media sources and the ICRC and other humanitarian agencies collected over a two-anda-half-year period. It describes 655 violent incidents affecting health care in 16 countries. "It reveals a more comprehensive picture than we've ever seen before," says lead author Dr. Robin Coupland, a former ICRC surgeon who now serves as its adviser on armed violence and the effects of weapons.

As health care professionals flee from war zones, communities lose health services just when they are most needed, the ICRC report states. For example, a single attack on doctors in Somalia in 2009 eliminated 150000 annual physician consultations, the study estimates. In the wartorn Democratic Republic of Congo, the denial of medical care due to violence against health workers kills 40000 people a month. In Afghanistan and Pakistan, vaccination programs cannot reach huge numbers of children due to conflict. In Iraq, where 628 health care professionals have been killed since the 2003 US-led invasion and 18000 doctors have fled, the ICRC says the health impacts have been "catastrophic."

In $33 \%$ of the 655 events reviewed in the new study, the violence was committed by state armed forces, while $36.9 \%$ of events were attributed to armed groups. Nongovernmental international health organizations suffered $34.5 \%$ of the reported events, while local health

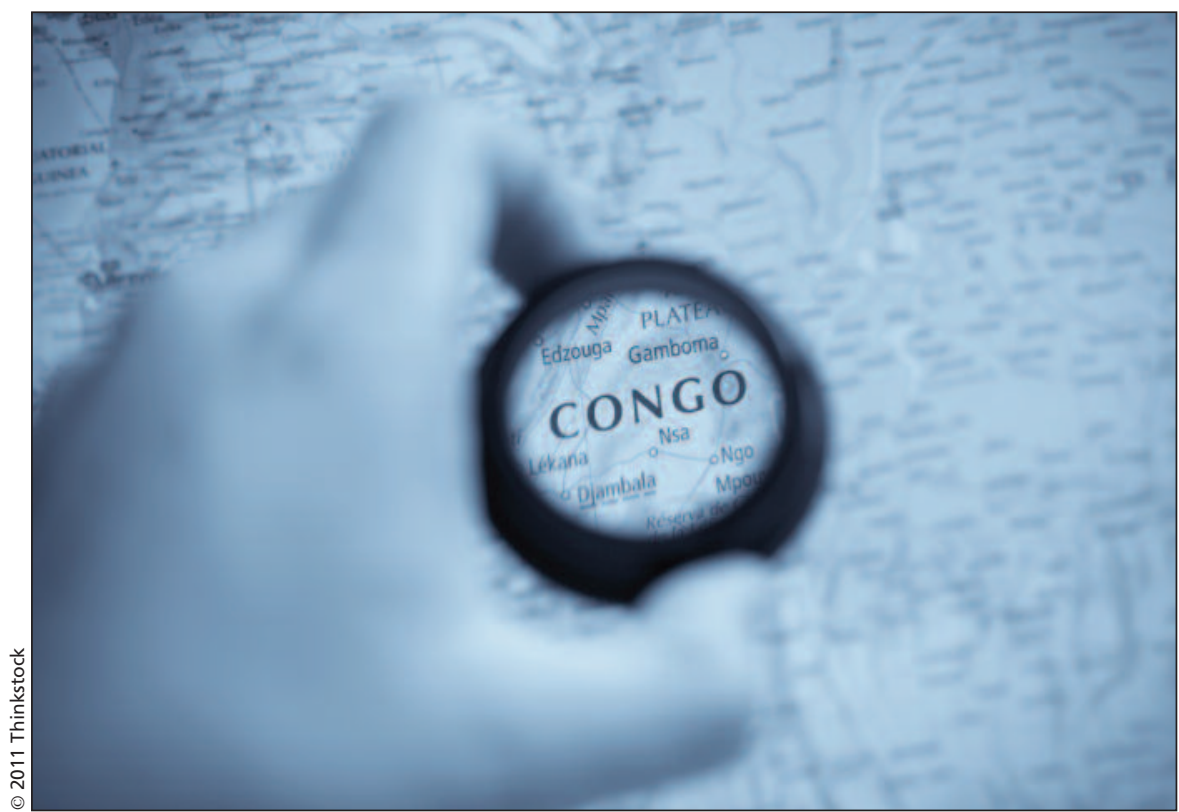

A new report is turning people's focus to war-torn areas, such as the Democratic Republic of Congo, where violence against medical workers has led to a loss of vital health services and is costing lives.

care services suffered $25.6 \%$, and Red Cross or Red Crescent organizations suffered $16.8 \%$. Hospitals and clinics were damaged in $17.7 \%$ of events, and ambulances were damaged in $4.9 \%$. Health care personnel accounted for $8.7 \%$ of 1834 people killed or wounded in the reported events analyzed.

The study does not provide countryspecific data, Coupland explains, because the ICRC cannot invite comparisons between countries due to its need to cooperate with governments and belligerents in order to gain access for its medical teams. And Coupland describes the data as approximate due to under-reporting of events in conflict zones, where "the bigger the event, the more it is denied." For their part, he notes, humanitarian agencies including the ICRC, for their own security, tend not to make public the less obvious incidents that affect them.

But in distilling a wide array of information without naming names, the study sheds light on an underappreci- ated issue, Coupland believes, and offers a factual "baseline" for a new ICRC campaign to reinforce the neutrality of health care by pressing governments and international bodies to bolster the Geneva Conventions.

"The information we've reviewed represents just the tip of the iceberg," Coupland says. "It paints a concise picture of the nature and extent of the problem. We're learning that this is one of the biggest humanitarian issues in conflict zones."

Nathan Taback, a University of Toronto biostatistician who managed data analysis for the new study, agrees it spotlights a huge problem for populations victimized when medics' neutrality is disregarded. "Until now there really has been no evidence base to understand this problem," he says. "We now have something to build upon." Taback says the next step is to persuade groups that offer health care in war zones, including the ICRC, to open their files much further. 
With no systematic reporting of assaults on medics in armed conflicts in place, efforts to confront the problem remain hamstrung, notes Leonard Rubenstein, a senior scholar at the Center for Public Health and Human Rights at the Johns Hopkins Bloomberg School of Public Health in Baltimore, Maryland.

In view of the growing understanding of the long-term effects of attacks on medics for population health and health systems, Rubenstein argued in a recent Lancet policy review that the World Health Organization should take responsibility for systematically gathering evidence in support of more concerted international action - specifically through the United Nations Security Council (Lancet 2010;375:329-40).

In highlighting an underappreciated issue affecting millions of people, the ICRC has succeeded in documenting the fact that "there is less and less respect for the Geneva conventions by all the actors, and the conventions may in fact have lost their value," notes Mike Fark, Toronto-based director of operations for Médecins Sans Frontières (MSF), an international medical relief organization working in 60 countries.

But pushing governments to reaffirm the conventions may be wishful thinking, Fark worries. To attract highlevel political support for concerted international action of the sort that has led to action on humanitarian issues in war zones, such as the Ottawa Treaty banning landmines, Fark thinks events in war zones such as Afghanistan, where North Atlantic Treaty Organization (NATO) troops incorporated medical programs as "force multipliers" into military strategies that were followed by attacks on health care work- ers, including one in which five MSF staff were killed in a deliberate attack in 2004, require acknowledgement and accountability. In Colombia in 2008, Fark notes, the government apologized publicly for violating the Geneva conventions after a Red Cross symbol was worn by a member of a military mission against rebels.

Most of all, Fark argues, much more needs to be known - especially by military planners and their political masters - about the effects of violence against health care at a population-wide level in conflict zones. "We need to focus on the consequences and not get bogged down in legalistic debates," he argues. "This issue is very real and very important for huge numbers of patients." - Paul Christopher Webster, Toronto, Ont.

CMAJ 2011. DOI:10.1503/cmaj.109-3964 